\title{
ЭНДОГЕННАЯ ИНТОКСИКАЦИЯ ПРИ РАЗЛИЧНЫХ СПОСОБАХ ЛЕЧЕНИЯ РАСПРОСТРАНЕННЫХ ФЛЕГМОН (ДОКЛИНИЧЕСКОЕ ИССЛЕДОВАНИЕ)
}

\author{
(C) Балин В.Н. ${ }^{1}$, Каршиев Х.К. ${ }^{2}$, Музыкин М.И. ${ }^{3}$, Иорданишвили А.К. \\ ${ }^{1}$ Национальный медико-хирургический Центр им. Н.И. Пирогова, Москва; \\ ${ }^{2}$ Городская клиническая больница, Ташкент, Узбекистан; \\ ${ }^{3}$ Военно-медицинская академия им. С.М. Кирова, Санкт-Петербург \\ E-mail: muzikinm@gmail.com
}

\begin{abstract}
В статье проведен анализ влияния методов лечения распространенных околочелюстных флегмон на показатели эндогенной интоксикации. Доклиническое исследование выполнено на лабораторных животных с целью оценки некоторых способов лечения в сравнительном аспекте. В ходе исследования определялись биохимические показатели крови, сорбционная способность эритроцитов, а также проводилось исследование среднемолекулярных пептидов на 1-е, 5-е и 8-е сутки. Результаты проведенных исследований показали, что у животных распространенные флегмоны сопровождаются развитием выраженной эндогенной интоксикации. Установлено, что комплексная терапия, включающая местное орошение послеоперационных ран раствором гипохлорита натрия при сочетании с ультрафиолетовым облучением крови наиболее благоприятно влияет на течение раневого процесса и в большей мере способствует нормализации показателей эндогенной интоксикации.
\end{abstract}

Ключевые слова: одонтогенные гнойно-воспалительные заболевания, сепсис, околочелюстная флегмона, одонтогенная инфекция, гипохлорит натрия, экспериментальная флегмона.

\section{ENDOGENIC INTOXICATION IN VARIOUS METHODS OF MANAGING WIDESPREAD PHLEGMONS (PRE- CLINICAL TRIAL) \\ Balin V.N. ${ }^{1}$, Karshiyev H.K. ${ }^{2}$, Muzykin M.I. ${ }^{3}$, Iordanishvili A.K. ${ }^{3}$ \\ ${ }^{1}$ N.I. Pirogov Russian National Medical Surgical Center, Moscow; ${ }^{2}$ City Clinical Hospital, Tashkent, Uzbekistan; \\ ${ }^{3}$ S.M. Kirov Military Medical Academy, St. Petersburg}

The influence of treatment methods in widespread perignathic phlegmons on indicators of endogenic intoxication is analzyed in the article. The preclinical trial is conducted on laboratory animals for the purpose of comparative assessing some methods of treatment. Biochemical indicators of blood and sorption ability of erythrocytes were defined, and also the research of middlemolecular peptides on 1, 5 and 8 days was conducted during the research. The results of the conducted researches showed that in animals the widespread phlegmons were accompanied by developing the expressed endogenic intoxication. It was established that the complex therapy including local irrigation of postsurgical wounds with sodium hypochlorite solution when combined with ultra-violet radiation of blood influences the course of a wound process and contributes to normalization of endogenic intoxication indicators.

Keywords: odontogenic pyoinflammatory diseases, sepsis, perignathic phlegmon, odontogenic infection, sodium hypochlorite, experimental phlegmon.

Воспалительные процессы в челюстнолицевой области в той или иной степени сопровождаются явлениями эндогенной интоксикации $[6,7,9]$. Эндогенная интоксикация, связанная с поступлением в кровь фракций эндотоксинов лизосомального происхождения и полипептидов средней молекулярной массы - продуктов тканевого распада, определяет не только течение болезни, но и ее прогноз $[4,8,12]$.

Эти обстоятельства диктуют необходимость проведения комплексной оценки общих и местных расстройств, а также разработки новых патогенетически обоснованных эффективных методов лечения острых одонтогенных гнойновоспалительных заболеваний челюстно-лицевой области с осложненным течением, способствующих благоприятному исходу при реабилитации таких пациентов [5, 13].
Цель исследования состояла в проведении сравнительного анализа влияния различных средств лечения распространенных экспериментальных флегмон на эндогенную интоксикацию организма.

\section{МАТЕРИАЛЫ И МЕТОДЫ ИССЛЕДОВАНИЯ}

Исследование проведено на 30 кроликах-самцах породы шиншилла в возрасте от 1 до 2 лет, массой 2,5-3,0 кг, которые содержались в стандартных условиях вивария, питались одинаково, что соответствовало общепринятым в России правилам и нормам содержания экспериментальных животных. Хирургические мероприятия проводились в два этапа под местной и внутривенной анестезиями с соблюдением правил и требований, 
предъявляемых к оборудованию, инструментарию, асептике и антисептике, в соответствии с ныне действующими «Правилами произведения работ с использованием экспериментальных животных» (приказ Министерства здравоохранения № 755 от 12 августа 1977 г.).

На первом этапе эксперимента под местным обезболиванием производилось моделирование распространенной околочелюстной флегмоны у лабораторных животных по общепринятой методике [1]. После нарастания клинических признаков заболевания (на втором этапе) под внутривенным обезболиванием осуществляли вскрытие и дренирование околочелюстной флегмоны с проведением общепринятой комплексной терапии $[3,11,12]$.

Животные были разделены на контрольную (интактные кролики) - 6 животных и основную группы. В зависимости от проводимого лечения в основной группе были выделены 4 подгруппы по 6 экспериментальных животных в каждой. Всем животным основной группы исследования проводилась общепринятая комплексная терапия распространенной околочелюстной флегмоны включающая хирургическое пособие и консервативные методы лечения. Помимо этого, животным 1-й подгруппы проводилось ежедневное одноразовое орошение после-операционной раны свежеприготовленным раствором гипохлорита натрия $\left(\mathrm{NaClO}_{3}\right)$, 2-й подгруппе в комплекс лечения включали внутривенное лазерное облучение крови (ВЛОК) и местную однократную обработку раны раствором $\mathrm{NaClO}_{3}$, в 3-й подгруппе проводилось ежедневное двухразовое орошение послеоперационной раны свежеприготовленным раствором гипохлорита натрия, в 4-й подгруппе помимо двухразового орошения $\mathrm{NaClO}_{3}$ применялось ультрафиолетовое облучение крови (УФОК).

Раствор гипохлорита натрия получали при помощи аппарата «Эсперо-1» (Россия). Ультрафиолетовое облучение крови проводили при помощи лазерного аппарата ДРТ-240 (Россия) по следующей методике. В начале выполнялось взятие крови шприцем из бедренной вены животного (из расчета 3 мл крови на 1 кг массы тела) с последующим проведением ультрафиолетового облучения крови и внутривенного введения ее животному по одному разу в день. Курс лечения состоял из пяти процедур. ВЛОК проводили при помощи аппарата ЛТМ-01 («Анод», Россия). Мощность излучения на выходе световода составляла 8 милливатт, время облучения - одна минута на сеанс.

Биохимические исследования крови проводили в 1-е, 5-е и 8-е сутки после начала лечения. Сорбционную способность эритроцитов (ССЭ) определяли по методу ТогайбаеваКургузкина (1987). Среднемолекулярные пептиды исследовали по методу Габриэлян (1981) [2].

Полученные данные по каждому пациенту заносились в базу данных программного пакета Microsoft Access. Статистическую обработку производили с применением программного пакета Statistica for Windows 7.0. Анализ результатов исследования производили согласно методическим рекомендациям по математикостатистической обработке данных медицинских исследований [9]. Вычисляли среднюю арифметическую $(\bar{X})$, среднюю ошибку среднего арифметического $\left(S_{\bar{x}}\right)$. Значимость различий между группами определяли с помощью непараметрического критерия U-критерия Манна-Уитни, Различия между сравниваемыми группами считались достоверными при $\mathrm{p}<0,05$.

\section{РЕЗУЛЬТАТЫ ИССЛЕДОВАНИЯ И ИХ ОБСУЖДЕНИЕ}

У всех экспериментальных животных опытной подгруппы при моделировании у них «распространенных» околочелюстных флегмон отмечены значительные изменения в показателях эндогенной интоксикации. Так, на 1-е сутки формирования «распространенной» флегмоны у экспериментальных животных значение ССЭ оказалась выше, чем у контрольной группы $(\mathrm{p}<0,05)$ в среднем на $34,3 \%$ (табл. 1$)$.

Включение в комплексную терапию при местном лечении орошения ран раствором гипохлорита натрия (2-я подгруппа) на 5-е сутки лечения не приводило к достоверному снижению значения ССЭ $(\mathrm{p}>0,05)$. На 8-е сутки эксперимента в этой группе животных наблюдалось достоверное снижение уровня ССЭ $(\mathrm{p}<0,05)$, но тем не менее эти показатели на 19,1\% превышали аналогичные значения, полученные у животных контрольной группы. Концентрация СМП в 1-е сутки эксперимента у животных 1 -й подгруппы опытной группы на $32,3 \%(\mathrm{p}<0,01)$ была повышенной по сравнению с интактными животными. На 5-е сутки после начала лечения у животных 1-й подгруппы содержание СМП достоверно снизилось $(\mathrm{p}<0,01)$, но эти показатели на $22,1 \%$ превышали значения, полученные у животных контрольной группы $(\mathrm{p}<0,05)$. На 8-е сутки у животных первой подгруппы было отмечено значительное снижение содержания СМП. Таким образом, включение в комплекс терапии $\mathrm{NaClO}_{3}$ привело к значительному снижению показателей эндогенной интоксикации у животных 1-й подгруппы основной группы. 
Таблица 1

Динамика показателей эндогенной интоксикации на фоне различных комбинаций комплекса лечебных мероприятий при экспериментальных распространенных околочелюстных флегмонах

\begin{tabular}{|c|c|c|c|c|}
\hline & & & & казатели \\
\hline & ппа больных & Сроки наблюдения & $\begin{array}{c}\text { Сорбционная } \\
\text { способность } \\
\text { эритроцитов }\end{array}$ & Среднемолекулярные пептиды \\
\hline & оольная группа & Интактные & $0,40 \pm 0,022$ & $0,20 \pm 0,012$ \\
\hline & & 1-е сутки & $31,46 \pm 0,44$ & $0,206 \pm 0,003$ \\
\hline & 1-я подгруппа & 5-е сутки & $42,26 \pm 1,26^{*}$ & $0,272 \pm 0,006^{*}$ \\
\hline & & 8-е сутки & $39,02 \pm 0,94^{*}$ & $0,252 \pm 0,006^{*, \wedge}$ \\
\hline$\stackrel{\widetilde{g}}{\Xi}$ & & 1-е сутки & $37,59 \pm 0,97^{*, \wedge}$ & $0,237 \pm 0,004^{*, \wedge, \circ}$ \\
\hline 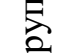 & 2-я подгруппа & 5-е сутки & $44,93 \pm 0,62 *$ & $0,276 \pm 0,005^{*}$ \\
\hline$\sum^{2}$ & & 8-е сутки & $36,80 \pm 1,45^{*, \wedge}$ & $0,229 \pm 0,006^{*, \wedge}$ \\
\hline 营 & & 1-е сутки & $34,04 \pm 1,03 *, \wedge, \mathrm{x}$ & $0,221 \pm 0,005^{*, \wedge, x}$ \\
\hline 乎 & 3-я подгруппа & 5-е сутки & $45,11 \pm 0,40^{*}$ & $0,280 \pm 0,005^{*}$ \\
\hline రे & & 8-е сутки & $39,77 \pm 0,36^{*, \wedge}$ & $0,272 \pm 0,003 *$ \\
\hline & & 1-е сутки & $38,05 \pm 0,22^{*, \wedge, \circ}$ & $0,242 \pm 0,010^{* \wedge, \circ}$ \\
\hline & 4-я подгруппа & 5-е сутки & $45,15 \pm 0,46^{*}$ & $0,280 \pm 0,004 *$ \\
\hline & & 8-е сутки & $32,66 \pm 1,00^{\wedge, \sim}$ & $0,212 \pm 0,001^{* \wedge \wedge}$ \\
\hline
\end{tabular}

Примечание: * - различия относительно данных интактной группы значимы $(\mathrm{p}<0,05), \wedge$ - различия относительно данных на 1 -е сутки значимы ( $<0,05,{ }^{\circ}-$ различия относительно данных на 5 -е сутки значимы $(\mathrm{p}<0,05),{ }^{\mathrm{x}}-$ различия относительно данных животных с КТ+ВЛОК $+\mathrm{NaClO}_{3}(\mathrm{p}<0,05), ~ \sim$ - различия относительно данных животных с $\mathrm{KT}+\mathrm{NaClO}_{3}(\mathrm{p}<0,05)$.

Результаты исследования, полученные в ходе эксперимента у животных 2-й подгруппы с распространенными околочелюстными флегмонами на 1-е сутки эксперимента, показали, что уровень ССЭ на 43,5\% превышал значения животных контрольной группы. На 5-е сутки комплексного лечения с включением ВЛОК и местного орошения ран раствором $\mathrm{NaClO}_{3}$ у животных наблюдалось выраженное снижение уровня ССЭ, однако эти значения $(\mathrm{p}<0,05)$ были выше, чем аналогичные показатели контрольной группы $(\mathrm{p}<0,05)$. В конце лечения на 8 -е сутки, было отмечено дальнейшее снижение уровня ССЭ, но ее уровень по-прежнему на $8,2 \%$ превышал значения группы контроля.

Содержание СМП в 1-е сутки исследования у животных 2-й подгруппы опытной группы превышал уровень контроля на $33,9 \%(\mathrm{p}<0,05)$. На 5-е сутки лечения отмечалось снижение содержания СМП в крови $(\mathrm{p}<0,05)$, но его концентрация на $11,1 \%$ превышала контрольные значения $(\mathrm{p}<0,05)$. По завершении лечения, на 8-е сутки отмечалось дальнейшее снижение содержания СМП, но его концентрация попрежнему превышала значения контроля $(\mathrm{p}<0,05)$.

При включении в состав комплексной терапии распространенной флегмоны двухразового орошения раны раствором $\mathrm{NaClO}_{3}$ (3-я подгруппа опытной группы) в 1-е сутки наблюдения отмечалось повышение уровня ССЭ на $43,4 \%$ по сравнению с показателем контроля $(\mathrm{p}<0,01)$. На 5-е сутки эксперимента не наблюдалось достоверное снижение значения ССЭ (табл. 1), но тем не менее ее уровень на $26,4 \%$ был выше, чем в контрольной группе $(\mathrm{p}<0,01)$. На 8 -е сутки эксперимента отмечено снижение уровня ССЭ по сравнению с предыдущим сроком $(\mathrm{p}<0,05)$, но ее уровень был еще на 20,9\% выше значений, полученных у животных контрольной группы $(\mathrm{p}<0,05)$.

В этой же подгруппе в 1-е сутки исследования содержание СМП на - 35,9\% превышало значения контрольных показателей. На 5-е сутки комплексного лечения отмечалось снижение концентрации СМП, хотя оно превышало концентрации контроля в этот срок эксперимента на $32,0 \%$. К 8-м суткам комплексного лечения показатели содержания в крови СМП значительно снизились.

При исследовании 4-й опытной подгруппы животных с распространенными околочелюстными флегмонами, для которых в комплекс лечебных мероприятий было включено УФОК и двукратное орошение ран раствором $\mathrm{NaClO}_{3}$, на 1 -е сутки эксперимента отмечалось увеличение уровня ССЭ, в среднем на $43,5 \%$, по сравнению с контрольными значениями ( $<<0,01)$. На 5 -е сутки комплексного лечения в этой подгруппе наблюдалось выраженное снижение уровня ССЭ $(\mathrm{p}<0,01)$, которое достоверно не отличалось от 
значений, полученных у интактных животных группы контроля $(\mathrm{p}>0,05)$.

В конце комплексного лечения на 8-е сутки эксперимента уровень ССЭ соответствовал этому показателю в контрольной группе. Содержание СМП на 1-е сутки у животных 4-й подгруппы было повышено $(\mathrm{p}<0,001)$ по сравнению с контрольными значениями на $35,9 \%$. На 5-е сутки комплексного лечения отмечено снижение этого показателя, уровень которого лишь незначительно достоверно превышал значения интактных животных в контрольной группе. В конце эксперимента значения исследованных показателей не отличались от показателей интактных животных.

Проведенное доклиническое исследование показало, что распространенные околочелюстные флегмоны сопровождаются развитием выраженной эндогенной интоксикации. Сравнительный анализ влияния различных методов лечения на динамику показателей эндогенной интоксикации при распространенных околочелюстных флегмонах позволил установить, что общепринятая комплексная терапия при включении в ее состав двухразового орошения раны раствором гипохлорита натрия на 1-5-е сутки эксперимента не приводит к выраженной положительной динамике изменения показателей эндогенной интоксикации. В то же время при использовании для лечения животных с распространенными околочелюстными флегмонами в дополнение к общепринятой терапии комбинации методов местной дезинтоксикации, ультрафиолетового облучения крови и орошения ран раствором гипохлорита натрия отмечена полная нормализация изученных показателей на 8-е сутки эксперимента, что позволяет рекомендовать данную методику для апробации в клинической практике челюстно-лицевой хирургии при комплексном лечении больных, страдающих одонтогенными околочелюстными полифлегмонами.

\section{ЛИТЕРАТУРА}

1. Балин В.Н., Каричев Х.К., Иорданишвили А.К., Музыкин М.И. Доклиническое патоморфологическое изучение мягких тканей при лечении околочелюстных гнойно-воспалительных заболеваний // Вестник Российской Военно-медицинской академии. - 2016. - № 4 (58). - С. 137-140.

2. Богатов В.В., Бурова Н.М. Интегральная схема оценки эндотоксического синдрома у больных с флегмоной челюстно-лицевой области // Стоматология. - 2013. - № 2. - С. 33-35.
3. Забелин А.С., Райнаули Л.В. Выраженность эндогенной интоксикации в зависимости от микробной этиологии флегмон челюстно-лицевой области // Росс. Стоматологический журнал. - 2003. - № 2. C. $40-42$.

4. Каршиев Х.К., Балин В.Н., Иорданишвили А.К. Динамика показателей функционального состояния печени у больных с одонтогенными гнойновоспалительными заболеваниями челюстно-лицевой области, осложненными сепсисом // Якутский медицинский журнал. - 2016. - № 4. C. 56-58.

5. Миронов П.И., Руднов В.А. Проблемы и перспективные направления коррекции медиаторного ответа при сепсисе // Анестезиол и реаниматол. 1999. - № 3. - С. 54-57.

6. Музыкин М.И., Иорданишвили А.К., Рыжак Г.А. Периоститы челюстей и их лечение. - СПб. : Человек, 2015. - 112 с.

7. Оковитый, С.В., Музыкин М.И., Иорданишвили A.K. Совершенствование комплексного лечения острого одонтогенного периостита у людей старших возрастных групп // Стоматология. 2012. - № 6. - С. 63-66.

8. Савельев В.С. Сепсис. Классификация, клиникодиагностическая концепция и лечение. Практ. рук-во. - М. : МИА, 2011. - 352 с.

9. Юнкеров В.И., Григорьев С.Г. Математико-статистическая обработка данных медицинских исследований. - 2-е изд., доп. - СПб. : ВМедА, 2005. - 292 c.

10. Cachovan G., Böger R.H., Giersdorf I., Hallier O., Streichert T., Haddad M., Platzer U., Schön G., Wegscheider K., Sobottka I. Comparative efficacy and safety of moxifloxacin and clindamycin in the treatment of odontogenic abscesses and inflammatory infiltrates // Antimicrobial Agents and Chemotherapy. - 2011. - Vol. 55, N 3. - P. 1142-1147. - doi: 10.1128/AAC.01267-10.

11. Glass C.A., Perrin R.M., Pocock T.M., Bates D.O. Transient osmotic absorption of fluid in microvessels exposed to low concentrations of dimethyl sulfoxide // Microcirculation. - 2006. - Vol. 13, N 1. - P. 29-40.

12. Krautsevich, L., Khorow $O$. Clinical aspects, diagnosis and treatment of the phlegmons of maxillofacial area and deep neck infections // Otolaryngol. - 2008. Vol. 62, N 5. - P. 545-548. - doi: 10.1016/S00306657(08)70311-1.

13. Sánchez R., Mirada E., Arias J., Paño J.R., Burgueño $M$. Severe odontogenic infections: epidemiological, microbiological and therapeutic factors // Med. Oral. Patol. Oral. Cir. Bucal. - 2011. - Vol. 16, N 5. P. 670-676.

14. Seppänen L., Rautemaa R., Lindqvist C., Lauhio A. Changing clinical features of odontogenic maxillofacial infections // Clin. Oral Invest. - 2010. Vol. 14, N 4 - P. 459-465. - doi: 10.1007/s00784009-0281-5. 